\title{
Prediction of erosiveness and rate of development of new erosions in early rheumatoid arthritis
}

\author{
T T MÖTTÖNEN
}

From the Department of Medicine. Central Hospital, SF 40620 Jyväskylä, Finland

SUMMARY Fifty eight patients suffering from a recent onset of rheumatoid arthritis (RA) were studied. Fifty six patients were followed up for 24 months and two for 18 months. Erosions weres detected in 17 patients at the onset and at the end of the follow up period the number of patientio with erosions was 44. The erosiveness in the joint groups studied was as follows: metatarsopha $\rightarrow$ langeal (MTP) (36 patients), metacarpophalangeal (MCP) (22), proximal interphalangeal (PIP) (21), interphalangeal (IP) joints of first toes and wrists (13), elbows and knees (two), ancP shoulders, ankles, and hips (one). Erosiveness in the feet was twice that in the fingers, and the erosions in the feet appeared at an earlier phase of disease. Destructions favoured the dominano hand. Swelling in the PIP joints appeared to be a better predictor of erosiveness than joint? tenderness. The number of joints to become eroded was significantly increased in the patient已 with flexor tenosynovitis in the hands. Erythrocyte sedimentation rate (ESR) was more closel 500 related to progression of joint damage than $C$ reactive protein (CRP) or haemoglobin. The rate of development of new erosions was the same in seronegative and seropositive patients. II addition, HLA-DR4 allele did not correlate either with seropositivity or with erosiveness Adequate antirheumatic drug treatment (gold in most instances) was not able to restrain the erosive process despite decreased rheumatoid disease activity.

Key words: tenosynovitis, HLA-DR4, Mallya index, ESR, CRP, rheumatoid factor, join辰 swelling, joint tenderness.

The clinical course of rheumatoid arthritis (RA) is fluctuating and the prognosis unpredictable. The concept of rheumatoid activity is usually linked with the inflammatory features of RA, but its accurate estimation is problematic and laborious. Rheumatoid activity is usually assessed by composite indices consisting of symptoms, clinical findings, and laboratory test results. ${ }^{1}$ '

Characteristically, RA affects peripheral joints, and the destruction of joint structures, demonstrable on $x$ ray films, is the most important feature in the prognosis. Appearance of early erosions correlates with unfavourable prognosis, ${ }^{3}$ whereas stabilisation of the erosive changes at an early stage of the disease predicts a favourable outcome. ${ }^{4} \mathrm{~A}$ close relation between global assessment of joint activity and development of radiological destruc-

Accepted for publication 26 January 1988.

Correspondence to Dr T T Möttönen. Department of Medicine. Central Hospital, SF 40620 Jyväskylä. Finland. tions during a follow up period of three years has been reported. ${ }^{5}$

The purpose of this prospective study was $(a) \mathrm{t}(\stackrel{\varrho}{\varrho}$ test whether erosiveness can be predicted by clinica? means, $(b)$ to define the rate of development of new erosions in various joints, $(c)$ to analyse the relations between erosiveness and clinical rating of rheuma를 toid activity, occurrence of the HLA-DR4 allele, th@ titre of rheumatoid factor (RF), a number of laboratory measures reflecting disease activity, and the duration of chrysotherapy.

\section{Patients and methods}

Sixty consecutive patients with newly diagnose of definite or classical rheumatoid arthritis ${ }^{6}$ were in cluded in the study. One of the patients was found tof have reactive arthritis and another patient was los@ from the follow up. The final group thus consisted o 58 patients with polyarthritis ( 41 women, 17 men) Their ages ranged from 17 to 78 years (mean 48 ) and 
duration of disease from 2 to 24 months (mean 8). Thirty eight patients were seropositive by the Waaler-Rose test $(>1 / 32)$ at least once in serial tests.

None of the patients had received second line antirheumatic drug treatment earlier. Sodium aurothiomalate treatment (intramuscular injections of $10,20,30$, and $50 \mathrm{mg}$ weekly up to $13 \mathrm{mg} / \mathrm{kg}$ body weight and thereafter $50 \mathrm{mg}$ monthly) was instituted in 54 patients, while three patients were initially treated with hydroxychloroquine $(300 \mathrm{mg}$ daily) and one patient with a non-steroidal anti-inflammatory drug only. Other antirheumatic drugs used in case of intolerance or unresponsiveness were as follows: auranofin $(6 \mathrm{mg}$ daily, $\mathrm{n}=6)$, sulphasalazine $(2 \mathrm{~g}$ daily, $n=19)$, D-penicillamine $(300-450 \mathrm{mg}$ daily, $\mathrm{n}=8$ ), azathioprine ( $2 \mathrm{mg} / \mathrm{kg}$ daily, $\mathrm{n}=2$ ). Low dose corticosteroid treatment (prednisolone $5-7.5 \mathrm{mg}$ daily) was instituted in six patients.

CLINICAL ASSESSMENT

The patients were examined by the author at the onset of the study and thereafter at six monthly intervals ( 56 patients for 24 months and two patients for 18 months). Clinical rheumatoid activity was estimated by a multivariate analysis including two subjective measures (morning stiffness, pain scale), two semiobjective measures (grip strength. Ritchie's articular index), ${ }^{7}$ and two objective measures (haemoglobin ( $\mathrm{Hb}), \mathrm{ESR}$ ) as described by Mallya and Mace (Mallya index). ${ }^{2}$ The scoring of clinical rheumatoid activity was determined as described earlier. ${ }^{8}$ The mean Mallya index during the follow up period was the mean value of the individual assessments.

The number of clinically active joints (tender or swollen, or both) was recorded at each visit. In addition, the tenderness of II-V PIP joints of the fingers and IP joints of the thumbs was scored from () to 3 points ${ }^{7}$ and the swelling due to effusion from 0 to 2 points (score 2 representing a hydroptic joint). The total score of tenderness and swelling of the PIP joints and IP joints of the thumbs was the sum of scores obtained at each assessment.

RADIOGRAPHIC METHODS

An $x$ ray examination of the hands and feet was made at $0,6,12,18$, and 24 months. Other joints were $x$ rayed when considered justifiable. The radiological destruction of the wrists, subtalar, I-V MCP, II-V PIP, IP joints of the thumbs, I-V MTP joints, and IP joints of the first toes was estimated and scored (from 0 to 5 points) according to the method of Larsen, Dale, and Eek.' An overall destruction index, the polyarticular Larsen index, was calculated at six monthly intervals for each patient by summing up the indices of the individual joints. The indices of subtalar and wrist joints were corrected using a coefficient of 5 . Thus the polyarticular Larsen index ranged from 0 to 260. Furthermore, the number of eroded joints was counted at each visit.

The following laboratory tests were carried out at each visit: ESR by Westergren's method, CRP by quantitative immunoprecipitation. $\mathrm{Hb}$, and WaalerRose titre.

Serological typing for HLA-DR alleles was made according to standard microlymphocytotoxicity test by commercial antisera. Mononuclear cells for HLA typing were isolated from heparinised blood by Ficoll-Hypaque gradient centrifugation and B cells for HLA-DR typing by further depletion of cells forming rosettes with 2-aminoethylisothiouronium treated sheep red blood cells.

\section{STATISTICAL METHODS}

Decision matrices were constructed to indicate the number of clinically active joints on the development of new erosions. Positive predictive values of the scores of tenderness and swelling to predict the development of new erosions were calculated from these tables. 10

The relations between longitudinal fluctuations in clinical and laboratory variables and grade of radiological destruction were assessed by Spearman's rank correlation. The significance of differences between the group medians was determined by Mann-Whitney's rank sum test. A binominal test was used to determine the significance between the number of eroded joints in the right and left extremities.

\section{Results}

DEVELOPMENT OF EROSIONS

Tables 1 and 2 show the cumulative appearance of erosions in each joint group. At least one eroded joint was found initially in 17 patients $(29 \%)$. The erosions were located in the hands in 10 , in the feet in nine, and in the wrists in two cases. The joints of 14 patients remained non-eroded throughout the follow up. No new erosions appeared in four patients with initially eroded joints, while in the remaining 40 patients an average of $5 \cdot 8$ new eroded joints was found. The first erosions appeared in the elbows at six months, in the shoulders and hips at 12 months, and in the ankles and knees at 18 months (Table 1).

The number of eroded small peripheral joints at entry was $43(2 \cdot 3 \%)$ but was increased to $243(13 \%)$ at two years (Table 2). Most erosions were located in the feet. No significant difference was found 
between the right and the left foot (65 $v 67$ erosions). On the contrary, in the hands a predominance of the right side was found (61 $v 50$ erosions; $p<0 \cdot 001)$. The rate of erosiveness in the fingers (MCP and PIP) was constant during the follow up, while in the MTP joints and the wrists the appearance of new eroded joints was greatest between six and 18 months. The V MTP joint was the single joint most often eroded (Table 2).

The mean value of the polyarticular Larsen index at the onset of the study was 4.4 (range $0-37$ ), rising to 19 (range $0-180$ ) at the end of the study. The value of the polyarticular Larsen index at 24 months increased to 20 or higher in 17 patients. In the patients with high initial Larsen index values further erosiveness appeared to be relatively low.

EFFECT OF TENDERNESS AND SWELLING ON EROSIVENESS IN THE II-V PIP AND IP JOINTS OF THE THUMBS

Table 3 presents the separate and combined effect of

Table 1 Cumulative number of patients with $R A$ with erosions in various joint groups during a follow up of 24 months*

\begin{tabular}{|c|c|c|c|c|c|}
\hline \multirow[t]{2}{*}{ Joint group } & \multicolumn{5}{|c|}{$\begin{array}{l}\text { Cumulative number of patients with } \\
\text { erosions at months: }\end{array}$} \\
\hline & 0 & 6 & 12 & 18 & 24 \\
\hline MCP jointst & 8 & 11 & 15 & 18 & 22 \\
\hline PIP joints $\dagger$ & 4 & 10 & 15 & 19 & 21 \\
\hline MTP jointst & 7 & 15 & 25 & 32 & 36 \\
\hline IP of first toe & 5 & 10 & 11 & 12 & 13 \\
\hline Wrists & 2 & 2 & 5 & 12 & 13 \\
\hline Elbows & 0 & 2 & 2 & 2 & 2 \\
\hline Shoulders & 0 & () & 1 & 1 & 1 \\
\hline Ankles & 0 & () & () & 1 & 1 \\
\hline Knees & () & () & () & 1 & 2 \\
\hline Hips & 0 & () & 1 & 1 & 1 \\
\hline
\end{tabular}

*Total number of patients was 58 .

$\dagger \mathrm{MCP}=$ metacarpophalangeal, $\mathrm{PIP}=$ proximal interphalangeal, $\mathrm{MTP}=$ metatarsophalangeal; $\mathrm{IP}=$ interphalangeal . joint tenderness and swelling on erosiveness. Joint $\frac{\text { ?क }}{\text { ? }}$ swelling appeared to be a better predictor of $\overrightarrow{\vec{s}}$ erosiveness than tenderness, and the predictiveness was not improved by using them together (Table 3 ). Swelling was palpated at at least two check ups in $25 \frac{\mathrm{m}}{\mathrm{c}}$ PIP or IP joints, of which 17 became eroded $(68 \%)$, while only $14 / 33(42 \%)$ of the joints became eroded 0 if swelling occurred at just one check up (Table 4).

\section{EFFECT OF TENOSYNOVITIS ON}

EROSIVENESS

Clinical examination showed flexor tenosynovitis ing the hands of 33 patients during the study. Signifi-o cantly more joints in the hands and feet of these

Table 3 Prediction of erosiveness by tenderness or swelling, or both, of 568 PIP joints of 58 patients with $R A$

\begin{tabular}{lllll}
\hline $\begin{array}{l}\text { Activity } \\
\text { score }\end{array}$ & $\begin{array}{l}\text { Number } \\
\text { of } \\
\text { joints }\end{array}$ & $\begin{array}{l}\text { Number } \\
\text { of } \\
\text { eroded } \\
\text { joints }\end{array}$ & $\begin{array}{l}\text { Number of } \\
\text { non-eroded } \\
\text { joints }\end{array}$ & $\begin{array}{l}\text { PPV } \\
(\%)\end{array}$ \\
\hline $\begin{array}{l}\text { Tenderness }(>3) \\
\text { Swelling }(>2)\end{array}$ & 88 & 26 & 62 & 5() \\
Tenderness and & 73 & 33 & 40 & 63 \\
swclling $(>5)$ & 65 & 31 & 34 & 6()
\end{tabular}

Tenderness and swelling are scored as presented in 'Patients andō methods'.

${ }^{*} \mathrm{PPV}=$ the calculated positive predictive value

Table 4 Occurrence and effect of palpable hydrops on the development of new erosions in 568 PIP joints during a follow up period of two years

\begin{tabular}{|c|c|c|}
\hline \multirow[t]{2}{*}{ Palpable hydrops } & \multicolumn{2}{|c|}{$\begin{array}{l}\text { Joints with new } \\
\text { erosions }\end{array}$} \\
\hline & No & $\%$ \\
\hline At two or more check ups & $17 / 25$ & 68 \\
\hline At one check up & $14 / 33$ & 42 \\
\hline Never observed & $21 / 510$ & 4 \\
\hline
\end{tabular}

Table 2 Number of eroded small peripheral joints in a group of 58 patients with RA (1854 joints) at the onset of the study and during a follow up period of two years

\begin{tabular}{|c|c|c|c|c|c|c|c|c|c|c|c|c|c|c|c|c|c|c|c|}
\hline \multirow{2}{*}{$\begin{array}{l}\text { Period of } \\
\text { follow up } \\
\text { (months) }\end{array}$} & \multicolumn{6}{|c|}{$M C P$} & \multirow{2}{*}{$\begin{array}{l}I P \\
I\end{array}$} & \multicolumn{4}{|c|}{$P I P$} & \multicolumn{5}{|c|}{$M T P$} & \multirow{2}{*}{$\begin{array}{l}I P \\
I\end{array}$} & \multirow{2}{*}{$\begin{array}{l}\text { Total } \\
\text { No }\end{array}$} & \multirow{2}{*}{$\begin{array}{l}\text { Cumulative } \\
\text { number of } \\
\text { eroded joints } \\
(\%)\end{array}$} \\
\hline & $I$ & $I I$ & & $I I I$ & $I V$ & $V$ & & $I I$ & $I I I$ & $I V$ & $V$ & $I$ & $I I$ & III & $I V$ & $V$ & & & \\
\hline 0 & 4 & 1 & & 0 & 1 & 3 & 0 & 3 & 1 & 2 & 5 & 0 & 2 & 4 & 4 & 7 & 6 & 43 & $2 \cdot 3$ \\
\hline 6 & 1 & 0 & & 1 & 1 & 2 & 0 & 5 & 4 & 3 & 3 & () & 3 & 3 & 2 & 8 & 6 & 42 & $4 \cdot 6$ \\
\hline 12 & 0 & 3 & $:$ & 3 & 3 & () & 0 & 0 & 6 & 2 & 3 & 3 & 6 & 7 & 7 & 6 & 2 & 51 & 7.3 \\
\hline 18 & 4 & 1 & . & 2 & 2 & 3 & 2 & 4 & 2 & 2 & 3 & 0 & 5 & 11 & 5 & 10 & 4 & 60 & $10 \cdot 6$ \\
\hline 24 & 0 & 2 & 1 & 6 & 2 & 3 & 1 & 2 & 3 & 5 & 2 & 0 & 2 & 4 & 5 & 9 & 1 & 47 & $13 \cdot 1$ \\
\hline Total & 9 & 7 & & 12 & 9 & 11 & 3 & 14 & 16 & 14 & 16 & 3 & 18 & 29 & 23 & 40 & 19 & 243 & \\
\hline
\end{tabular}


patients became eroded than in those of the rest of the patients $(5.4 \vee 3.7 ; \mathrm{p}=0.015)$. Accordingly, the polyarticular Larsen index of the patients with flexor tenosynovitis increased significantly more during the follow up period than in those without tenosynovitis $(p=0 \cdot 0038)$. No significant difference was found in the mean Mallya index, in the number of clinically active joints, or in any of the laboratory measures (CRP, ESR, RF) between the patients with or without tenosynovitis.

RELATION OF HLA-DR4 ALLELE, LABORATORY PARAMETERS, AND CLINICAI. DISEASE ACTIVITY TO EROSIVENESS

The prevalence of DR4 in this series was $54 \%$ (31/57). The allele was not found to be associated with the progression of joint damage or seropositivity. The mean values of ESR, Hb, and CRP correlated significantly with erosiveness (Table 5). The number of eroded joints of the 38 patients with a positive Waaler-Rose test at at least one check up did not differ significantly from that of repeatedly seronegative patients. In addition, no significant difference in the rate of erosiveness was observed between persistently seropositive $(n=20)$ and seronegative $(n=17)$ patients. The mean WaalerRose titre, however, was weakly related to the development of joint damage (Table 5). The clinical activity of RA measured by two different methods (Mallya index, number of clinically active joints)

Table 5 Relation between the mean values of ESR, $C R P, H b$, Waaler-Rose titre, Mallya index and its components, number of clinically active joints, initial values of the Mallya index and the polyarticular Larsen index and the increase of the polyarticular Larsen index and the number of new eroded joints during two years of follow up $(n=56)$

\begin{tabular}{|c|c|c|c|c|}
\hline & \multicolumn{2}{|c|}{$\begin{array}{l}\text { Increase in the } \\
\text { polyarticular } \\
\text { Larsen index }\end{array}$} & \multicolumn{2}{|c|}{$\begin{array}{l}\text { Increase in } \\
\text { the number of } \\
\text { eroded joints }\end{array}$} \\
\hline & $R s$ & p Value & $R s$ & p Value \\
\hline Mcan ESR & 0.425 & $<() \cdot()) 1$ & $(0.413$ & $<() \cdot()())$ \\
\hline Mcan Hb & -()$\cdot 375$ & ()$\cdot()() 4$ & $-0 \cdot 361$ & $0 \cdot(0) 5$ \\
\hline Mcan CRP & $(0.290$ & $(0 \cdot() 14$ & 0.322 & $0 \cdot(0) 17$ \\
\hline Mean Waaler-Rose titre & $(0.218$ & $0 .(15$ & $(0 \cdot 220$ & $(0 \cdot() 48$ \\
\hline Mean Mallya index & 0.534 & $<() \cdot(x) 1$ & $(0.578$ & $<() \cdot()() 1$ \\
\hline Mean number of & & & & \\
\hline clinically active joints & $(0.553$ & $<() \cdot()() 1$ & $(0.629$ & $<() \cdot()() !$ \\
\hline Mcan Ritchic's index & 0.466 & $<() \cdot()() 1$ & $(0 \cdot 449$ & $<() \cdot(x) 1$ \\
\hline Mcan morning stiffness & $(0.393$ & $0 \cdot(0) 3$ & 0.428 & $<() \cdot()) 1$ \\
\hline Mcan pain scale & $(0 \cdot 470$ & $<0 \cdot()(0) 1$ & $(0 \cdot 341$ & $(1) \cdot(1)(1)$ \\
\hline Mean grip strength & -0.425 & $<() \cdot()) 1$ & -()$\cdot 4()()$ & $0 \cdot(00) 2$ \\
\hline Mallya index at entry & $(0 \cdot 244$ & 0.033 & $(0.297$ & $0 \cdot() 12$ \\
\hline $\begin{array}{l}\text { Polyarticular Larsen } \\
\text { index at entry }\end{array}$ & $-0 \cdot() 48$ & NS & $0 \cdot() 66$ & NS \\
\hline
\end{tabular}

correlated significantly with erosiveness, and their correlation coefficients were higher than those of Ritchie's index, morning stiffness, pain scale, or grip strength. The polyarticular Larsen index at the onset of the study did not correlate with further erosiveness (Table 5).

\section{EFFECT OF GOLD TREATMENT}

Nineteen patients withdrew from gold treatment owing to adverse reactions and three owing to pregnancy. Chrysotherapy was ineffective in 11 patients. Thus only 21 out of 54 patients continued gold treatment throughout the follow up period. Thirty three patients received gold treatment for more than 12 months and 15 for less than six months. The increase of the polyarticular Larsen index during the follow up period was not significantly smaller in the patients receiving gold treatment throughout the follow up period (21 cases) than in those treated for less than six months (15 cases) $\left(\begin{array}{lll}7 & v & 13 \cdot 5\end{array}\right)$.

\section{Discussion}

Persistent synovitis and development of bone erosions are typical features of RA. Rheumatoid inflammatory activity can be assessed clinically and indirectly by various laboratory tests. Radiological judgment, however, is the objective method for estimation of permanent destructive changes.

In this series of 58 patients with recent onset RA eroded joints were found in 17 cases at the onset of the study. After a follow up of two years the number of patients with eroded joints had increased to 44 . In most cases (36 patients) the erosions were found in the foot joints. These results are in accordance with those presented in previous studies, ${ }^{3+}$

Erosiveness in the feet was twice that in the joints of the hands. New erosions usually appeared between six and 18 months in the feet, while in the hands the rate of erosiveness was fairly constant. The V MTP joint appeared to be the single joint to become most often eroded, confirming the findings of Thould and Simon."

There was significantly more joint destruction in the dominant hand, suggesting that mechanical stress is an important aggravating factor in the development of joint damage in RA. ${ }^{12}$ Recently, however, Buckland-Wright and Walker reported no difference in the number and area of erosions between the right and left extremities, in a study using quantitative macroradiographic examination. ${ }^{1 / 3}$

In the present study, in contrast with the data presented by Luukkainen and his coworkers, ${ }^{14}$ the grade of radiological destruction at entry did not predict further erosiveness. 
The appearance of new erosions was not arrested during the follow up period by adequate antirheumatic treatment. This shows that decline in clinical rheumatoid activity does not necessarily retard radiological disease progression. ${ }^{15}$

Swelling in the PIP joints appeared to be a better predictor of erosiveness than joint tenderness. This extends previous findings that joint swelling is a significant prognostic indicator. ${ }^{1617}$ On the other hand, it has recently been shown that clinical evaluation of MTP joints is arbitrary, whereas serial joint scintigraphies more accurately predict the development of new erosions. ${ }^{18}$

Tendon lesions in RA are not rare. In the present study clinical examination showed flexor tenosynovitis in the hands of most of the patients. The number of joints to become eroded was significantly increased in this group in comparison with the patients without tenosynovitis. No significant difference was found in the clinical activity of RA between the groups, suggesting that flexor tenosynovitis of the hands is an independent predictor of erosiveness.

The prevalence of the DR4 allele in this series was $54 \%$, which does not differ considerably from the figure presented by Gran and his coworkers. ${ }^{19}$ The presence of DR4 did not correlate with either seropositivity or erosiveness.

Although CRP appears to be a more sensitive measure of rheumatoid inflammatory activity than ESR, ${ }^{20} 21$ the present study suggests that ESR is associated more closely with erosiveness than CRP. Amos and his coworkers have shown that radiographical damage is more likely to occur when CRP and ESR are persistently raised. ${ }^{22}$ In their patients CRP was more predictive of joint damage than ESR, but the difference was not statistically significant. In the present study all the mean values of ESR, CRP, and $\mathrm{Hb}$ correlated significantly with erosiveness.

In a few prospective studies positive rheumatoid serology has been shown to correlate with the development of bone erosions. ${ }^{23-25}$ In addition, a high titre of RF appears to be associated with rapid radiological progression, ${ }^{26}$ though in other series IgM RF did not correlate with erosiveness. ${ }^{22}{ }^{27-29}$ In this investigation the degree of radiological destruction in the patients with a positive Waaler-Rose test did not differ significantly from that of the seronegative patients. It is difficult to find an explanation for the discrepancies in the studies mentioned above. The results of the study reported here support the concept that RF is not an important predictor of erosiveness, at least not in early RA.

The mean values of Mallya index and the number of clinically active joints correlated more closely with erosiveness than Ritchie's index, but, surprisingly, two subjective measures (morning stiffness $\overrightarrow{\vec{F}}$ and pain scale) were better predictors of erosiveness than CRP.

Chrysotherapy was instituted in nearly all of the $\frac{\bar{\sigma}}{\bar{n}}$. patients. The progression of joint damage during $\widetilde{\Phi}$ the follow up did not differ significantly between the patients receiving gold treatment throughout the follow up period and those treated for less than six $\overrightarrow{0}$ months. Sigler et al and Luukkainen et al have reported that gold treatment retards the progression of erosions in RA. ${ }^{30} 31$ Sigler's trial was placebo@ controlled, ${ }^{30}$ whereas in the present series most of $\overline{0}$ the patients intolerant to gold were subsequently treated with sulphasalazine, which also may slow the progression of radiological destruction. ${ }^{32}$ In the study by Luukkainen and others the follow up period was more prolonged (mean 66 months) and steroids and chloroquine were the concurrent agents. ${ }^{31}$

In conclusion, it seems that joint swelling, the $\frac{C}{\infty}$ number of clinically active joints, and the ESR are as good as, if not better than, the Ritchie index, the $\vec{\odot}$ Mallya index, and CRP as predictors of 'erosiveness'.

The author would like to thank Dr Jorma Ilonen for determination of HLA-DR alleles.

\section{References}

1 Lansbury J. Quantitation of the activity of rheumatoid arthritis. Am J Med Sci 1956; 232: 300-10.

2 Mallya R K. Mace B E W. The assessment of disease activity in rheumatoid arthritis using a multivariate analysis. Rheumatology and Rehabilitation 1981; 20: 14-17.

3 Fleming A, Crown J M. Corbett M. Prognostic value of early features in rheumatoid discase. $B r$ Med $J$ 1976; i: 1243-5. O

4 Brook A. Fleming A. Corbett M. Relationship of radiological 3 . change to clinical outcome in rheumatoid arthritis. Ann Rheum Dis 1977; 36: 274-5

5 Young A, Corbett M. Brook A. The clinical assessment of joint inflammatory activity in rheumatoid arthritis related to radio-윽 logical progression. Rheumatology and Rehabilitation 1980: 19: $14-19$

6 Ropes M W. Diagnostic criteria for rheumatoid arthritis. Ann Rheum Dis 1959; 18: 49-53.

7 Ritchie D M. Boyle J A. McInnes J M. et al. Clinical studies o with an articular index for the assessment of joint tenderness in $\mathrm{N}$ patients with rheumatoid arthritis. $Q J$ Med 1968; 37: 393-406. N

8 Hannonen $\mathbf{P}$. Möttönen T. Oka $\mathbf{M}$. Serum ferritin and free $\omega$ erythrocyte protoporphyrin in rheumatoid arthritis. Rheumatole Int 1986; 6: 185-8.

9 Larsen A, Dale K. Eek M. Radiographic evaluation of $\frac{\mathrm{C}}{\mathrm{C}}$ rheumatoid arthritis and related conditions by standard reference films. Acta Radiol /Diagn) (Stockh) 1977; 18: 481-91. :

10 Griner P F, Mayewski R J. Mushlin A I. Greenland P. Selection T and interpretation of diagnostic tests and procedures: principles $O$ and applications. Ann Intern Med 1981; 94: 557-92.

11 Thould A K, Simon G. Assessment of radiological changes in $\frac{\overparen{P}}{\mathbb{P}}$ the hands and feet in rheumatoid arthritis: their correlation with prognosis. Ann Rheum Dis 1966; 25: 220-8.

12 Martell W, Hayes J T. Duff I F. The pattern of bone erosion in

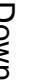

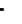


the hand and wrist in rheumatoid arthritis. Radiology 1965; 84: 204-14.

13 Buckland-Wright J C, Walker S R. Incidence and size of erosions in the wrist and hand of rhcumatoid patients: a quantitative microfocal radiographic study. Ann Rheum Dis 1987; 46: 463-7.

14 Luukkainen R, Kaarela K, Isomäki $\mathrm{H}$, et al. The prediction of radiological destruction during the early stage of rheumatoid arthritis. Clin Exp Rheumatol 1983; 1: 295-8.

15 Scott D L, Dawes P T, Fowler P D, Grindulis K A, Shadforth $M$, Bacon $P$ A. Anti-rheumatic drug and joint damage in rheumatoid arthritis. $Q J$ Med 1985; 54: 49-59.

16 Sharp J T. Lidsky M D. Duffy J. Clinical responses during gold therapy for rheumatoid arthritis. Arthritis Rheum 1982; 25: 540-9.

17 Ingeman-Nilsen M, Halskov O, Hansen T M, Halberg P, Stage $P$, Lorenzen I. Clinical synovitis and radiological lesions in rheumatoid arthritis. Scand J Rheumatol 1983; 12: 237-40.

18 Möttönen T T. Hannonen P. Toivanen J, Rekonen A. Oka M. Value of joint scintigraphy in the prediction of erosiveness in early rheumatoid arthritis. Ann Rheum Dis 1988; 47: 183-9.

19 Gran J, Husby G, Thorsby E. The association between rheumatoid arthritis and the HLA antigen DR4. Ann Rheum Dis 1983; 42: 292-6.

20 Walsh L, Davies P. McConkey B. Relationship between erythrocyte sedimentation rate and serum C-reactive protein in rheumatoid arthritis. Ann Rheum Dis 1979; 38: 362-3.

21 Mallya R K, de Beer F C, Berry H, Hamilton E, Mace W, Pepys M. Correlation of clinical parameters of disease activity in rheumatoid arthritis with serum concentrations of $\mathrm{C}$-reactive protein and erythrocyte sedimentation rate. J Rheumatol 1982: 9: 224-8.

22 Amos R, Constable T, Crockson R, Crockson A, McConkey B. Rheumatoid arthritis: relation of serum $\mathrm{C}$-reactive protein and erythrocyte sedimentation rates to radiographic changes. $\mathrm{Br}$ Med J 1977; i: 195-7.

23 Cats A, Hazevoet M. Significance of positive tests for rheumatoid factor in the prognosis of rheumatoid arthritis. Ann Rheum Dis 1970; 29: 254-60.

24 Wawrzynska-Pagowska J. Brzezinska B, Brozozowska M, et al. Observations on the symptoms and signs of carly rheumatoid arthritis in a prospective study. Acta Rheumatologica Scandinavica 1970; 16: 99-105.

25 Masi A, Maldonado J, Kaplan S, Feigenbaum S, Chandler R. Prospective study of the early course of rheumatoid arthritis in young adults. Semin Arthritis Rheum 1976; 4: 299-326.

26 Sievers K. The rheumatoid factor in definite rheumatoid arthritis. Acta Rheumatologica Scandinavica 1965:-9 (suppl): 1-121.

27 Jacoby R, Jayson M, Cosh J. Onset, early stages, and prognosis of rheumatoid arthritis: a clinical study of 100 patients with 11year follow up. Br Med J 1973; ii: 96-100.

28 Dawes P T, Fowler P D, Jackson R, et al. Prediction of progressive joint damage in patients with rheumatoid arthritis receiving gold or D-penicillamine therapy. Ann Rheum Dis 1986; 45: 945-9.

29 Árnason J A. Jónsson T, Brekkan Á. Sigurjónsson K, Valdimarsson $\mathrm{H}$. Relation between bone erosions and rheumatoid factor isotypes. Ann Rheum Dis 1987; 46: 380-4.

30 Sigler J W. Bluhm G B. Duncan H, Sharp J T, Ensign D C, McCum W R. Gold salts in the treatment of rheumatoid arthritis: a double-blind study. Ann Intern Med 1974; 80: 21-6.

31 Luukkainen R. Isomäki H. Kajander A. Effect of gold treatment on the progression of crosions in RA patients. Scand J Rheumatol 1977; 6: 123-7.

32 Pullar T, Hunter J A, Capell H A. Effect of sulphasalazine on the radiological progression of rheumatoid arthritis. Ann Rheum Dis 1987; 46: 398-402. 